facturer feels regret and pain at seeing work inefficiently performed, our national system of education will be incomplete.

All the labour now expended in watching work in progress, and in testing it when completed to see that it has not been scamped, is so much withdrawn from the real business of pro duction. Every rise, therefore, in the standard of thoroughness of a community means the saving of waste labour. But far greater than this will be the actual increase in the productive power when each gives his best endeavours to his share of the world's work. And greatest of all will be the gain in the nation's happiness, since he who works with his whole soul knows no drudgery.

The lesson to be taught is no new one-it was set many centuries ago; and hundreds of thousands a year will be well spent if the County Councils can succeed in bringing home to the hearts of us all this-" Whatsoever thy hand findeth to do, do it with thy might."

\section{PHOTOGRAPHY AS A BRANCH OF} TECHNOLOGY.1

THE invitation conveyed to me by your Council, to assist in promoting a scheme of photographic technical education of a more complete character than that provided by the elementary schools, is in such complete accord with the principles which I have always held, and which I have occasionally pro. mulgated through other channels, that I felt it an almost imperative duty to respond to the invitation in spite of the numerous other claims upon my time. For I believe that if the Photographic Society will throw itself with zeal into some wellorganized scheme in this direction a great benefit will be conferred upon the cause of technical education in this country. I will even go so far as to express the belief that a work of national importance may be accomplished.

It may perhaps appear as preposterous to dwell upon the importance of photography before the members of this Society as it would be for a inerchant to address the Chamber of Commerce on the importance of trade, or for a financier to lecture to an Irstitute of Bankers on the importance of banking. Nevertheless, it is a common experience that those who are actively engaged in the prosecution of some special kind of work often take a narrow view of their own labours; they have no time to take a bird's-eye view of the whole subject, and an independent outsider may sometimes do good service by gathering up the odds and ends of scattered observations and fitting them into their right positions in the general plan. If any justification is required from me for addressing a Society composed so largely of photographic experts, I need only plead that as a teacher of technical chemistry have felt it necessary to give full recognition to the claims of photography as an important branch of technology. It can no longer be ignored that photography has penetrated the arts and sciences to an extent that has raised it to an exalted position among technical subjects, and as such it has not yet received its proper recognition in this country. From the very daw $n$ of its discovery the importance of its applications was foreseen, although it is only in our own time that the realization of this importance is being witnessed. We need not commit ourselves to the extravagance of Paul Delaroche, the artist, who, during the excitement caused by the revelation of the Daguerreotype process, is said to have declared : "Painting is dead from this day!" The art of the painter has not been killed, but it may fairly be claimed that it has been aided by photography; the art of the engraver has been revolutionized by its means. The prophetic utterance of a writer in the Edinburgh Review for January 1843 has been fulfilled :-

"The art of Photography or Photogeny, as it has been called, is indeed as great a step in the fine arts as the steam-engine was in the mechanical arts; and we have no doubt that when its materials have becalne more sensitive, and its processes more certain, it will take the highest rank among the inventions of the present age."

All who are familiar with modern photographic methods will admit the truth of this prediction; the materials have been rendered more sensitive and the processes more certain. The sensitiveness has been increased to a degree that would probably astonish the writer of the passage quoted, and the

I An Address to the Photographic Society on February 2, by Prof. R. Meldola, F.R.S.

NO. I 62 , vOL. 45$]$ certainty of the processes is such that the amateur photographer exists by thousands. It is perhaps this last circumstance which is responsible for the identification of photography in the public mind with the taking of portraits and landscapes. These are no doubt very important applications of the subject, but photography is not synonymous with portraiture and the taking of scenery; if we allow this view of the subject to prevail, it cannot but have the effect of narrowing down the general estimate of its importance, and of thus injuring its claim to take high rank among technical subjects. We are here, I imagine, to proclaim the far-reaching importance of our subject. Everyone knows with what beautiful effect the photographer can reproduce a portrait or a piece of scenery, but what is not so generally known to the public at large is the enormous service that photography has rendered to other branches of science. If dwell therefore upon this application of the subject, it is not for the purpose of depreciating its application to art, but rather for the purpose of exalting both aspects.

The modern dry plate has insinuated itself into every branch of practical science; whenever a phenomenon of a temporary character has to be registered with absolute accuracy-where the human eye fails, owing to the faintness of the object, or the rapidity with which the phenomenon occurs, there the aid of the dry plate is invoked. The application of photography to astronomy has, as is well known, relieved the eye of the astronomer and curtailed the work of the observatory to an extent bordering on the marvellous. A faint nebula, which by eye observation may take many years of wearying labour to represent in the form of a drawing, in the course of a few hours impreses its image in all its fineness of detail on the photographic plate-a memorial for future ages of the true form of the nebula at the time of its being photngraphed. Stars which appear as points of lights in the telescope are shown by the photographic plate to be small nebulæ, and stars and nebulæ which have altogether eluded the most powerful telescopic search impress themselves on the sensitive film. All this and much more in the same direction is such familiar knowledge now that it is only necessary to mention the facts, nor need I remind you how the photographic plate is being utilized for the photo-astrographic survey of the heavens, and in astronomical spectroscopy for the permanent registration of the solar spectrum and the spectra of the stars. "The "Draper Memorial" is one of the latest examples of the utility of photography in the observatory ; it is no exaggeration 10 say that one of the grandest problems of modern science-the question of stellar evolution-will be rendered capable of scientific discussion by this application of the gelatino-bromide film. The modern astronomical observatory is in fact equipped for photographic work quite as much as for observational work, and the photographer has become as necessary as the observer.

In physics and in chemistry also the photographic plate has been added to the weapons of research. Here it has been used to record phenomena which occur with such rapidity as to elude visual perception. What would the Edinburgh Reviewer of 1843 have thought of the possibility of photographing a soap film in the act of breaking, or a liquid drop in the act of falling ? Yet, as you all know, Lord Rayleigh and Mr. Boys have succeeded in doing this. Or take again the application of the sensitive plate to the elucidation of the phenomena of gaseous explosions by Prof. Oettingen who, by using a rapidly rotating dry plate, was enabled to show the intermittent character of the flash produced by the explosion of hydrogen and oxygen. Profs. Liveing and Dewar have also succeeding in photographing the spectrum of a mixture of exploding gases. In spectrum analysis, in fact, the services which have been rendered by photography cannot be over estimated. The astronomer, the physicist, and the chemist must have for reference complete and accurate charts of the spectra of the chemical elements. The early maps of Bunsen and Kirchoff, and the splendid "Spectre Normale" of Angström were drawn by eye observation after years of laborious work, and with injury to the eyesight of the observers. These maps are now produced by photography without any tax upon the eyesight, and with an amount of detail that renders the early maps-executed with such painful labour -but mere skeletons as compared with their photographic re. presentatives. The spectra can moreover be compared fa: more readily and with much greater accuracy by the photographic method. The method of eliminating the lines in the spectrum of one element, due to the presence of a trace of some other element as an impurity, which we owe to Prof. Norman Lockyer, 
has only been rendered possible by photography. If the residual lines common to several elements, and which cannot be traced by this means to any known element, should lead to the dis. covery of new elements or to the resolution of known elements into simpler forms of matter, the credit must be given to the photographic method.

But it will be safer to confine ourselves to what photography has actually done for science than to attempt to enter the regions of speculation. The case to be made out is such a good one that there is no need to draw upon the imagination. Thus, again in the region of spectroscopy, the relationship between the constitutions of chemical compounds and their power of absorbing certain definite light waves, as investigated by Prof. W. N. Hartley, may be said to have been discovered by means of photography, because the absorption is, in the case of colourless liquids, exerted beyond the limits of the visible spectrum. In meteorology the photographic plate has also been of the greatest service, and a British Association Committee has been formed for the purpose of stimulating work in this direction. Most of those present are, no doubt, familiar with the more striking results achieved by meteorological photographers. The fleeting forms of clouds can be registered with absolute fidelity, and by an ingenious arrangement of electrically connected cameras the height and rate of motion of clouds has recently been determined by the aid of photography. The character of the electric discharge in the laboratory has been studied photographically by Mr. Shelford Bidwell and by Profs. Oliver Lodge and C. V. Boys, and the large-scale discharge of the lightning flash has been made to impress itself on the photographic plate. The results are known to all ; the conventional zigzag "fork" appears to have no existence in nature. The destructive effects of wind storms on buildings can also be studied in photographs with an amount of accurate detail that it would be impossible to represent by any other method; and I am informed by Mr. G. J. Symons that important conclusions concerning the nature of the atmospheric movement have been arrived at by the examination of such photographs.

Passing on to other applications of photography, it is obvious that in geographical and ethnological exploration the camera has become an essential part of the traveller's equipment. In geology again the aid of the photographer has been called in, and with such good results that a British Association Committee has been called into existence, and has been doing excellent work in collecting and registering geological photographs during the last two or three years. In these photographs sections are recorded with a fidelity which it would be impossible to equal except by laborious sketching. Where time is an object, as in the case of sections only temporarily exposed, the camera is invaluable. Moreover, the value of such photographs will increase with time in the same way and for the same reason as photographs of the starry heavens. For while the latter, taken at the time of the present celestial survey, will, by comparison with photographs taken in the far distant future, reveal relative movements among the stars, the geological photographs of the present period will by future comparison with the localities registered furnish incontestable evidence of the slow course of geological change.

In biology photography has been utilized with great advantage, and will no doubt become of still greater service in the future. There is no reason why the dry plate, which has al. ready largely superseded the eye in astronomy, should not also relieve the eye of the microscopist. Many biological works have been illustrated with great success by means of photomicrography, and even in purely systematic works, such, $\sigma_{\text {. }}$, as Marshall and De Nicéville's "Butterflies of India," photographic illustration has been adopted with success. In studying microscopic forms of life, where an evanescent phase of lifehistory may be full of profound significance, the photographic plate might well replace the eye in those cases where prolonged and fatiguing observation has hitherto been found necessary. The fleeting phases of expression, of such importance in comparative psychology, have been caught and fixed on the photographic plate with a natural fidelity that it would have been impossible to attain without snch aid. Mr. Darwin's work on "The Expression of the Emotions" was, as you are aware, illustrated by photography even before the dry plate had been worked up to its present exalted degree of sensitiveness.

The application of photography to the analysis of the movements of animals has been made familiar through the remarkable photographs which Mr. Muybridge has on many occasions brought under our notice in this country. Among other results recently achieved, I need only refer to those wonderful pictures of animals in motion, taken by Messrs. Marey and Anschiitz. Such results as these are not only interes ing illustrations of the high state of perfection to which modern photography has been developed, but they are of the highest value in elucidating the mechanism of animal movement, and of the flight of birds. The introduction of photography into this branch of animal mechanics has led to a complete revision of pre-existing conventional notions, and the indirect effect of such photographic analysis of the phases of motion on the work of the artist is of an impcrtance that cannot be over-estimated.

In the department of anthropology photography has served for the faithful registration of race types, and Mr. Francis Galton's method of composite portraiture is familiar to all. In his recent studies of "finger marks" in +connection with heredity, $\mathrm{Mr}$. Galton has also found it indispensable to work from photographic enlargements.

This imperfect sketch of the scientific applications of photography might well be followed by a much more extended list of its achievements in the domain of art. But I do not feel myself justified in taking up more time in telling you what you already know, and there are no doubt many present who are far more competent to deal with this aspect of the subject than I am. I cannot help thinking, however, that it would materially help the cause of technical instruction in the desired direction if some competent authority among you were to draw up a complete statement of the benefits which have accrued to art, both abstract and applied, by the introduction of photographic and photo-mechanical methods. ${ }^{2}$

To all who are interested in the advancement of art and of science, photography appeals, therefore, as a branch of technology of the first order of importance ; in saying that it appeals to art and to science for such recognition, it is evident that it appeals to the nation at large. Even to the "pure scientist," who is supposed to lose interest in a discovery as soon as it becomes practical, i.e. commercial, this subject appeals for support, for from the study of the photographic processes themselves many important contributions to physics and chemistry have been made, and still greater results may be expected to follow from the investigations of scientific men in this direction. From its purely practical side the claim of photography to be considered as a branch of technology will receive additional support when it is remembered how many distinct branches of manufacture it draws upon, or has, indeeed, actually called into existence. Consider how it is dependent on the optician for the manufacture of lenses; consider, again, the special branch of cabinetmaking and joinery whieh it has created in order to supply cameras and other instruments; remember, also, the boon which photography has conferred upon the chemical manufacturer by the demand for fine chemicals which it has created. Neither must it be forgotten that $a$ new and by no mean. unimportant development in the manufacture of paper, gelatine, and albumen bas arisen through the introduction of photography.

From every point of view, therefore, photography claims to be placed on the same basis as other branches of technology. The Photographic Society, I am happy to see, fully recognizes this in the recent action which it has taken, and which is expressed in the report of the Affiliation Committee. I consider this an excellent move in the right direction. But it is easy enough for the Society to recognize the technical importance of its own snbject; the difficulty is to move public opinion, and to convince the nation that we are behind other countries in this respect. The first step is to draw up and circulate widely an account of what is being done for photographic technical instruction on the Continent. I had intended when first invited to lecture here, to offer some such statement, but I was ylad to read in a recent number of your Journal that this task had been undertaken by Mr. Warnerke, and I hope that some means will be taken to bring his report under the notice of those interested in technical education. It is clear from what has already been attempted by this Society, and from the opinions which have been expressed on all sides by those whose voices carry the weight of authority, that nothing short of a Photographic Institute will meet the requirements of the case. This I most

I Prof. du Bois-Reymond deals with this in the address referred to. Some of Prof. Marey's recent results are described in NATURE, vol. xlv. p. 228 .

${ }^{2}$ Since the above was written Prof. E. du Bois-Reymond's address to the Royal Academy of Sciences of Berlin on the "Relation of Natural Science to Art," has appeared in NATURE, vol. xlv. pp. 200 and 224.

NO. I 162 , VOL. 45] 
earnestly hope will bis the end and aim of every movement made by the Society. In the Cantor Lectures, which I had the honour of delivering before the Society of Arts in the spring of last year, I alluded to the absence of such an establishment in this country as "remarkable"; before this Society I am tempted to express myself more strongly, and to stigmatize its absence as a national disgrace.

Of course we all have more or less distinct ideas of what the functions of such an Institute would be. It is premature as yet to speak of the details of an institution which exists only in our aspirations. But whatever may be the final outcome of the movement which has been started, the whole duty of such an institution might be summarized in the statement that its work would consist in spreading a knowledge of all that is known concerning photography, and in investigating that which is unknown. In other words, its duties would be, as in the case of kindred institutions, teaching and investigating. Without wishing in any way to intrude my opinions into the deliberations of your Council, I thought that I might with advantage avail myself of the present opportunity of submitting my own views with respect to this question of technical education in photography. In giving expression to these views $I$ have in mind the consideration that the remarks which I may apply to our special subject apply to many other related technical subjects, and that the course which may be adopted in the starting of such an Institute as that which we all wish to see come into existence, may have a wide and important influence on existing notions concerning the whole question of technical education.

In the first place, then, let me express the hope that any action taken by this Society in the direction of photographic technology, will be of the highest possible character. This may appear to you quite an unnecessary caution, but it involves a question of principle which it is very important to ventilate. After many years of apathy in this country, and after experiencing the inevitable consequence that we were being beaten in many branches of applied science by our Continental competitors, we underwent a few years ago a kind of revival in technical education. One outcome of this agitation was the foundation by the City and Guilds of London of that Institute in whose service I have the honour of treing employed. It is not for me to dwell upon the results which have flowed from the inauguration of that Institute, but it is no exaggeration to say that the wave of public opinion which raised it into existence is still surging throughout the country. The last decade has witnessed the rapid multiplication of technical classes and colleges, the foundation of technical associations, the growth of polytechnics, and last of all, the diversion by the Government of the funds derived from the beer and spirit duty in the direction of technical education. The result of all this is that the means of technical education are being spread broadcast throughout the land.

Now it is one of our national characteristics that when we once wake up to the circumstance that we are behind other countries in any matter affecting our industries-or, I might say, when we have this unpleasant truth brought home to us by the superior workmanship or lower prices of our competitors-we are apt to seek remedial measures to recover our lost ground by what might be called indiscriminate and impulsive rushes. I am afraid that the technical education movement has, to some extent, been of this impulsive character. I am not going to be rash enough here to attempt to lay down any precise definition of what is meant by technical education; but a few months ago, the Duke of Devonshire, then Lord Hartington, made a speech at the opening of "he Storey Institute, at Lancaster, in the course of which he said that technical education was not the teaching of any particular trade or handicraft, but rather the scientific principles underlying the trade or handicraft. I think this fairly represents the opinions of those who have considered the subject, and I hope that this definition will be borne in mind in any movement which this Society may inaugurate.

If now we review the situation, it will appear that the general spread of this educalional movement may be taken as an indication that we intend to give battle to our competitors, and that we look to technical education to enable us to carry on the industrial campaign. So far so good ; but our competitors, be it remembered, have been actively carrying on this branch of education during our long years of apathy. We have taken up our weapons rather tardily, and, as I just said, somewhat impulsively, and if we hope for success it behoves us to examine these weapons critically, in order to make sure that we are fighting on equal terıns. In other words, are we adopting the best methods of technical education? This is the question which should be put in the foremost place before any measure can be taken by this Society in the much needed direction of photorraphic technology.

So far as concerns those technical subjects in which, as in photography, chemistry is largely, if not entirely, the underlying science, I am bound to confess that the impulsive character of the technical education movement to which I have referred, may, if not properly directed, run us altogether off the right track. One of the greatest functions of this Society would be to prevent such a calamity by diverting the tide of public opinion into the proper channel for its own particular subject of photography. The ideal technologist is a man who possesses a good general knowledge of the principles of those sciences underlying his industry, together with an expert special knowledge of his own subject. The first step in the training of a technologist is, therefore, to lay the broad foundation of general principles, and then to erect upon this foundation the superstructure of special knowledge. You must understand that I am attempting only to define an ideal technical training, having more especial reference to those subjects connected with, or based upon, chemical science. In the present state of affairs it cannot be denied that there are large classes to whom this method cannot be applied; there are specialists in every industry who know little or nothing of the scientific principles underlying their occupation, and in such cases the method may have to be reversed, and the instruction may have to proceed from unscientific specialism to scientific generalisation. But this method is, in my belief, only a makeshift which it may be expedient to adopt to meet existing conditions-it is not technical education in the strict sense of the word education, but the tinkering up of a system which has been bad from the beginning. It is only when we can deal with the student just starting on his career as a technologist that the true method can be applied ; as things are we have many years of tinkering work before us, and it is to the rising generation of younger technologists that the future industrial welfare of the country is committed.

The danger ahead which threatens the true cause of technical education appears to me to be this:-The resources of the country are being too much frittered away in the multiplication of machinery for imparting elementary instruction, and the higher specialisation which alone will save us in the end is being crippled thereby. The elementary groundwork must be laid, and this work, as far as it is being dune, cannot be done too well. But it is absurd to suppose that we shall recover our lost position in any branch of industry by scattering broadcast a knowledge of elementary science, and there leaving matters to stand. A technologist is nothing-at least in any of the subjects with which I have had c.nnection-unless he has the means of superadding more advanced specialisation to his general grounding. So far as the chemical industries of this country are concerned, a few highly-trained specialists are worth more than an entire army of elementary certificated teachers or prizewinners. We are expending so much energy over our foundations that there is but little left for raising the superstructure. We are arming our industrial fighters with weapons which are as pop-guns compared with the heavy ordnance of our competitors. Unless those who are responsible can be made to see that the elementary training in general principles is, in a large number of subjects, quite useless unless the higher specialization is equally well catered for, we shall be no better off in these branches of technology than we were before. The elementary training bears to technology the same relationship that the tuning of the instruments does to the overture. There is a great deal of twanging and blowing going on all over the country, but, as yet, comparatively few indications of a finished performance. There is enough money in the hands of the County Councils at the present time to support technical institutes adapted to local requirements on a scale which would bear comparison with the polytechnics and technical high schools of the Continent. If each county, or group of counties, had its central technical institute, manned by competent specialists, then the elementary training might bear real fruit, and we should look forward with greater hope to the restilt of the campaign on which we have entered. It is not difficult to see how the fight will end if we persist in blazing away with this elementary small shot in response to the ponderous missiles of our industrial competitors.

Out of the haze of generalities which I am afraid $I$ have been

No. I I62, VOT. 45] 
led to inflict upon you, the central idea concerning the proposed action of this Society 1 hope begins to loom with a more or less definite form. It is not for you to add to the general tinkling of small bells, but it remains for you to bring together a strong staff of expert ringers who can give us a good loud peal on the chimes. You will, I hope, sooner or later, set an example in technical education in your own subject--which so admirably lends itself to the purpose-which shall act indirectly on all related subjects, by showing how much of the real work of technology begins after the elementary and advanced training have been completed. The instruction imparted under the existing arrangements is good as far as it goes, but from your point of view it must be regarded as the means of supplying the raw materials out of which the technologist of the future is to be moulded. It is not your province to assist in the multiplication of elementary classes, but to set the seal of efficiency on the existing organizations.

I should have but little justification for addressing you as I have did I not feel what a splendid opportunity lies before you for raising the level of at least one important branch of tech. nology. Still less should $I$ be justified in responding to your invitation did I not offer some suggestions which may be of use in furthering your object. The Photographic Institute, such as we desire, would be an establishment thoroughly equipped for the best practical instruction, well provided with appliances for carrying on research in every department of the subject, and having attached to it the most competent specialists in every branch. The staff need not be numerous at first ; a chemist, an optician and physicist, an expert in photo-mechanical processes, and an artist would represent the chief departments. Your committee or governing body would know the right men to select; if they cannot be found in this country you may have to go abroad for them. This course may appear ignominious, but if it has to be adopted so much the better ; it will bear practical witness to the necessity of having the means of raising such men in our own country. The ideal institute may be a slow growth, but every effort should be made to establish it. The Photographic Society has already taken the initiative by proposing an affiliation with kindred Societies. This scheme should be energetically pushed forward, and every means adopted for urging the importince of the claims of photography to have a recrgnized technological centre. I venture to think that an impetus would be given to the movement if representatives of the Camera Club, the Photographic Convention of the United Kingdom, and of the numerous photographic Societies of the metropolis were invited to another conference, such as was held last year, but with the special object of forming a joint committee, under whose authority a further appeal might be made for public and private support. If only a moderate fund could be raised at first, operations might be commenced. Surely the numerous firms which have come into existence through the general introduction of photographic processes, and the large body of wealthy amateurs who practice the art as a pastime, might be sufficiently interested in the movement to give it their support.

It only remains now to bring these suggestions to a practical issue. We are such a very practical nation that unless something tangible is offered, the foundation of the Institute may be indefinitely delayed; as yet there is nothing of the kind in existence-there is no organized work being done that appeals directly to the patriotism and to the pockets of those to whom you may legitimately look for assistance. But elementary photography is being taught in connection with technical schools and classes all over the country. A good beginning might be inade if under the auspices of the joint committee a few first-class specialists were enlisted and authorized to give short courses of demonstrations to those affiliated Societies or in those centres which desired to receive such instruction. The local centres might fairly be asked to make the necessary arrangements and to bear the small expense of local organization; the fund raised by the joint committee would be well spent at first in defraying the costs of a few special lectures. You may have some difficulty in laying your hands on the right men for this work; I need hardly remind you that the whole success of this initial movement would depend upon your sending only the most highly qualified specialists. You must have men who can teach the teachers and convince practical photographers that underlying the practice of their art are broad scientific principles which it is their interest to know something about. These preliminary peripatetic courses must be regarded in the light of missionary efforts, having for their object not the multiplication of photographic operators, but the awakening of the elementary and advanced student to the higher aspec's of their subject. It is desirable to have this function of the lectures well understood at the outset ; the experts who are entrusted with this work will know well enough that it is impossible to make a technologist out of a student, however enthusiastic he may be in his subject, simply by giving him a course of lectures.

If the system of itinerant instruction which I have suggested can only be fairly started, even on a small scale, one important function of the Institute will have been inaugurated. It will have a claim upon the practical educationalist as a teaching body; it will appeal more specifically to the promoters of technical education and to those public bodies which have voluntarily or by Act of Parliament identified themselves with this movement. It is certainly discouraging-I may say discreditable-when we see the magnificent scale on which the photo-technical Institutes of Berlin and Vienna have been founded and equipped, that in this country, whatever the importance of the subject, public recognition and support come only after success has been achieved by private enterprise. I am afraid you will have to reckon with this national characteristic, which, although retarding advancement in many directions, is so far good that it calls forth the most strenuous exertions to insure success at the outset of every new movement. Upon the success of your first small undertaking will depend the larger ultimate success which we all look for.

One other suggestion occurs to me which may help to strengthen your hands. I have said that instruction in photography is already being given in many technical schools; this instruction is more or less of an elementary character. It seems feasible to combine with the proposed courses of special lectures a system of inspectorship which might be carried out by the same staff. Your lecturers would be recognized experts, capable of advising such schools as to methods of teaching and of cooperating with local centres in the selection of the most highly qualified teachers. I am sure that most centres would be only too glad to avail themselves of the knowledge and experience thus placed at their service. If you begir operations on these lines at first-if you can carry on this combined system of skilled teaching and inspection successfully for a few years, your claim for permanent establishment and endowment as a Photographic Institute cannot but receive that support from public bodies to which your educational efforts will have entitled you, and which in other countries is given by the State.

\section{UNIVERSITY AND EDUCATIONAL INTELLIGENCE.}

OxFORD.-Commencement of Hilary Term.-The usual notices are being issued this week to undergraduates to come into residence the end of next week, full term commencing February 8 . The notices state that Hilary Term will be of the usual length-eight weeks. Residence for Easter Term will begin on April 22. The dates for the examinations in Hilary Term have been fixed as follows: Preliminary in Natural Science, March 14; First Public Examination for Honours in Classics, March 17 ; Responsions, March 31 .

It has been stated that this is the first time the date of the commencement of Term has been postponed by reason of an epidemic since the date of the Great Plague in the seventeenth century, when a whole term was abandoned.

The Senior Mathematical Scholarship has been awarded to Mr. A. E. Jolliffe, B.A., late Scholar of Balliol and Fellow of Corpus Christi ; Proxime Accessit, Mr. R. C. Fowler, B.A., of New College, to whom the examiners have awarded Lady Herschel's Prize for Astronomy. Mr. H. H. I'iggott, Corpus Christi, was awarded the Junior Mathematical Scholarship and to Mr. H. A. Pritchard, of New College, the Junior Mathematical Exhibition.

CAMBridge. - Mr. F. W. Dyson, B.A., of Trinity College, bracketed Second Wrangler, I889, and Smith's Prizeman, $189 \mathrm{I}$, has been elected to the second Isaac Newton Studentship, tenable from April 15, 1892, to April 15, 1895.

Mr. J. H. Flatber, late Master of Cavendish College, has been appointed Assistant-Secretary for the Local Examinations. An Exhibition of fifty guineas a year is offered by the Clothworkers' Company for proficiency in physical science. It is tenable for three years by a non-collegiate student of Oxford or Cambridge. Application is to be made to the Censor, Fitzwilliam Hall.

An influential syndicate has been appointed to obtain plans

NO. I I 62 , voL. 45$]$ 